\title{
PRÊMIO FLORESTAN FERNANDES 2018: apresentação
}

\section{FLORESTAN FERNANDES AWARD 2018: presentation}

Terry Mulhall *

O Prêmio Florestan Fernandes, concedido pela Coordenação do Curso de Ciências Sociais, teve origem no início dos anos 2000. O seu objetivo principal era de dar reconhecimento e de prestigiar a pesquisa feita pelos discentes. As monografias, uma vez defendidas, permaneciam arquivadas na Coordenação, e, como consequência, não havia divulgação ou disseminação da produção discente no seio da comunidade acadêmica. $\mathrm{O}$ Prêmio foi concebido como tentativa de superar essa falta de visibilidade, e nesses termos, pode-se dizer que tenha logrado êxito, embora ainda haja muito a ser feito para ampliar e melhorar a divulgação e o compartilhamento dos resultados dessas pesquisas.

Uma das coisas que chama atenção — quando olhamos em retrospectiva para o acervo das monografias produzidas no curso - é a riqueza da produção discente desde a sua criação. Ao longo de 22 anos, desde 1998, a Coordenação do Curso de Ciências Sociais tem pelo menos 376 monografias defendidas acerca de assuntos os mais diversos. Trata-se, em geral, de pesquisas que iluminam a nossa própria cidade ou outras cidades do estado da Paraíba. Alguns títulos chamam atenção, como por exemplo: A identidade e os estigmas dos trabalhadores da construção civil (Tânia Valéria de Oliveira Custódio, 2010); Fotojornalismo de homicídio: uma leitura compreensiva (Edísio Ferreira de Farias Júnior, 2001); “Tudo baratinho, freguês!”: um estudo sobre o trabalho dos camelôs em João Pessoa (Weruskha Abrantes Soares Barbosa, 2001); Movimento hip hop em João Pessoa - ritmo, atitude e poesia: em busca da identidade (Rivoneide Ferreira de Lima, 2004); Micaroa: o carnaval fora de época de João Pessoa (Luciana Delmiro Martins, 2004); “Anos da chibata": perseguição aos cultos afro-pessoenses: o surgimento das federações (Stênio José Paulino Soares, 2006)); Já cumpri minha obrigação: um olhar antropológico sobre o cemitério da comunidade Nossa Senhora da Guia, Lucena-PB (Uliana Gomes da Silva,

\footnotetext{
* PHD em Sociologia pela London School of Economics. Professor do Departamento de Ciências Sociais, e coordenador do Curso de Ciências Sociais da Universidade Federal da Paraíba/Brasil. E-mail: terrymulhall@hotmail.com.
} 
2014). Isso, para citar apenas algumas dentre tantas outras com o mesmo nível de importância.

Assertiva que pode ser verificada ao olharmos a qualidade das monografias defendidas em 2018. Foram quinze trabalhos avaliados pela comissão examinadora, e, diante da dificuldade para escolher apenas uma, resolveu selecionar três, conforme quadro abaixo:

\begin{tabular}{|c|l|l|l|}
\hline ATRIBUIÇÃO & \multicolumn{1}{|c|}{ AUTOR } & \multicolumn{1}{|c|}{ TÍTULO } & ORIENTAÇÃO \\
\hline PREMIADO & $\begin{array}{l}\text { Edmilson Gomes } \\
\text { da Silva Junior }\end{array}$ & $\begin{array}{l}\text { Do laboratório à autoria: projeto } \\
\text { JABRE e experiência } \\
\text { cinematográfica no interior da } \\
\text { Paraíba }\end{array}$ & Aécio Amaral \\
\hline MIENÇÃO & $\begin{array}{l}\text { Pedro Cardoso } \\
\text { Saraiva Marques }\end{array}$ & $\begin{array}{l}\text { A política de juros no Brasil: uma } \\
\text { abordagem empírica da conexão } \\
\text { entre juros e inflação }\end{array}$ & Ítalo Fittipaldi \\
\hline MENÇÃO & $\begin{array}{l}\text { José Mauro de } \\
\text { Pontes Pompeu }\end{array}$ & $\begin{array}{l}\text { Devoração e mobilidade: discursos } \\
\text { antropofágicos }\end{array}$ & $\begin{array}{l}\text { Aécio Amaral } \\
\text { José H. Artigas de } \\
\text { Godoy }\end{array}$ \\
\hline
\end{tabular}

Como Coordenador do Curso, gostaria de parabenizar os premiados e todos que concorreram para a sua persistência. Sabe-se que os/as estudantes de ciências sociais têm que enfrentar muitas barreiras, sociais e intelectuais, para concluir a graduação, fato comprovado pela taxa significativa de evasão que se abate sobre o curso. Gostaria, também, de parabenizar as professoras e o professor que compuseram a banca avaliadora: Ana Montoia, Luciana Ribeiro e Thiago Panica, pela dedicação e competência do trabalho realizado.

O trabalho agraciado com o Prêmio — Jabre: Laboratório Paraibano para Jovens Roteiristas - é de autoria de Edmilson Gomes. O projeto Jabre de extensão universitária da UFPB, objeto da sua pesquisa, teve início em 2011, e visava descentralizar a produção cinematográfica para que ela pudesse chegar a pequenas cidades do estado da Paraíba a partir de oficinas que oferecessem formação e apreciação em cinema destinado aos jovens dessas localidades. A monografia mostra como o laboratório possibilitou a esses jovens terem vivências mediadas pelo cinema que possibilitaram uma experiência de autoria. Segundo Edmilson, essas experiências de autoria contribuem para que tenhamos hoje uma cena de produção cinematográfica paraibana mais diversa e descentralizada, com circulação e reconhecimento nos âmbitos nacional e internacional. 
Para Edmilson, a interiorização do cinema paraibano, impulsionada pelo Projeto Jabre, deve ser lida a partir da dinâmica de produção e circulação característica do chamado capitalismo flexível e suas consequências para o que alguns autores denominam de "cinema pós-industrial". Como parte da indústria do simbólico, o cinema pós-industrial acentua, de um lado, maior potencial de descentralização do acesso aos meios de produção cinematográfica, e assim reanima o debate artístico e sociológico acerca do cinema independente (em relação aos ditames da grande indústria) e autoral — cinema este marcado pela horizontalidade na produção e pela autonomia estética e temática. Por outro lado, o cinema pós-industrial também expõe características de precarização do trabalho artístico, as quais corroboram a tendência crescente à precarização do trabalho em geral no capitalismo contemporâneo. Nesse cenário, a pesquisa mostra a importância social e artística que uma política cultural orientada desde o Estado democrático, no seio da universidade pública e gratuita, pode ter.

Pedro Marques, hoje doutorando em Ciência Política, recebeu menção honrosa com a monografia A política de juros no Brasil: uma abordagem empírica da conexão entre juros e inflação. $\mathrm{O}$ objetivo da sua monografia é avaliar empiricamente o impacto da política pública de juros do Banco Central do Brasil para o intervalo de 1999 a 2017 a luz da teoria da justiça de John Rawls.

O autor submeteu o artigo, que se veicula nesta edição, como artigo livre, antes da realização e divulgação dos resultados do Prêmio Florestan Fernandes. O manuscrito seguiu todas as fases do fluxo editorial, passando pelo desk review, e foi avaliado por dois pareceristas. Foi, então, aceito para publicação. Pouco tempo depois, os editores foram informados que sua monografia havia sido agraciada com a menção honrosa do referido prêmio, o que faria jus à publicação na Seção Prêmio Florestan Fernandes. Assim, em diálogo com o autor, resolveu-se que o artigo já aprovado, seria deslocado para esta seção, o que evitaria a repetição do conteúdo.

Em se tratando das elevadas taxas básicas de juros observadas nos últimos tempos, a pesquisa questiona a sua eficácia em termos do impacto na taxa de inflação. Juros básicos altos implicam receitas superavitárias altas. Criou-se um cenário no qual os recursos dos contribuintes são redistribuídos para titulares da dívida pública sem um retorno social. $\mathrm{O}$ autor argumenta que tal intervenção gera uma redistribuição desigual de recursos, o que motiva a julgá-la à luz de um dos critérios rawlsianos de justiça, segundo o qual, uma instituição é justa 
se suas desigualdades são justificáveis em virtude dos benefícios que trazem aos grupos menos favorecidos. A parte de todo o orçamento destinado ao pagamento de juros poderia ter sido empregada em outras políticas com um desempenho melhor. Isso ressalta a importância de uma agenda de avaliação crítica de políticas públicas que também contemple o setor financeiro, incluindo o Banco Central do Brasil.

O trabalho Devoração e mobilidade: discursos antropofágicos, também agraciado com menção honrosa, é de autoria de José Mauro de Pontes Pompeu. Trata-se de um estudo que estima a contribuição de Oswald de Andrade para o pensamento social e político brasileiro do início do século XX, tendo como base os elementos antropo-filosóficos que lastreiam parte considerável de sua obra, sobretudo aquilo que se poderia chamar de uma protossociologia. Oswald de Andrade é aqui visto como o formulador de uma antropofilosofia original, uma antropologia política antropofágica, que erige, a um só tempo, um pensamento político que hoje pode ser lido como decolonial e uma reflexão filosófica "metacultural".

Ao enfocar as dimensões decolonial e de reflexão filosófica metacultural da obra do ícone do modernismo artístico brasileiro, José Mauro explora as instâncias discursiva e normativa presentes na ideia de antropofagia. A partir de uma abordagem ensaística, o trabalho identifica como essas duas instâncias estiveram na base de movimentos artísticos e culturais fundamentais no Brasil do século XX, do Teatro Oficina à Tropicália e outras manifestações que contribuíram e ainda contribuem para a formatação e compreensão da cultura brasileira. Do ponto de vista de sua relevância teórica, José Mauro argumenta ainda que a antro-filosofia política e antropofágica de Oswald deve ter sua contribuição para as ciências sociais contemporâneas, estimada a partir de um cotejo com os pressupostos que orientam as teorias decoloniais e pós-estruturalistas.

Das pesquisas feitas pelos discentes do curso, surgem duas questões que merecem uma breve reflexão. A primeira é a questão que pode ser chamada de "democratização do conhecimento". Como fazer com que o conhecimento produzido na universidade seja usufruído pela comunidade fora de seus muros? Fazê-lo se aproximar do público mais vasto sem ser açambarcado por interesses mercantilistas em privatizar a "propriedade intelectual", 
ou ser utilizado por movimentos populistas com pautas anticientíficas, como a "militarização das escolas". Não temos receita pronta a oferecer, mas o que está se tornando claro é que, para evitar o avanço da privatização, ou até coisa pior, a defesa da autonomia deve ser conciliada com uma maior participação social.

Isso levanta a segunda questão, que trata da "finalidade" do Curso de Ciências Sociais. Para que serve o conhecimento produzido por seus discentes? Para que servem as 376 monografias defendidas ao longo dos últimos 23 anos? Pala alguns, o valor do conhecimento social está na sua contribuição para políticas públicas. Para outros, o seu valor pode ser mensurado pela sua contribuição para o crescimento econômico, para o lucro das empresas com parcerias com a universidade, ou até em termos do retorno financeiro para graduados. Não é minha intenção desmerecer essas finalidades, porém o problema é que para os que estão somente interessados nelas, as ciências sociais nunca terão o seu próprio valor, e ficarão em posição subalterna no "campo científico".

Pensamos que o valor principal das nossas monografias pode ser encontrado num outro sentido. Servem como espelho da realidade social em que a gente vive. Uma pesquisa sobre cemitérios, camelôs ou federações religiosas vai além da sua contribuição científica, embora isso seja necessário. Num contexto histórico, no qual a realidade social é negada, no mundo de fake news, no qual as redes sociais digitais se tornaram a fonte principal de informação, a produção da ciência social comprometida com o conhecimento social adquire uma importância crítica. Como C. Wright Mills (1982, p. 199) nos lembra: "ninguém está fora da sociedade: a questão é saber o lugar que se ocupa dentro dela".

\section{Referências}

MILLS, C. Wright. A imaginação sociológica. 6. ed. Rio de Janeiro: Zahar Editores, 1982.

Recebido em: 24/05/2021.

Aceito em: 24/05/2021. 